\title{
BMJ Open The association of statin use with reduced incidence of venous thromboembolism: a population-based cohort study
}

\author{
Riitta Lassila, ${ }^{1}$ Antti Jula, ${ }^{2}$ Janne Pitkäniemi, ${ }^{3}$ Jari Haukka ${ }^{3}$
}

To cite: Lassila R, Jula A, Pitkäniemi J, et al. The association of statin use with reduced incidence of venous thromboembolism: a population-based cohort study. BMJ Open 2014;4: e005862. doi:10.1136/ bmjopen-2014-005862

- Prepublication history for this paper is available online. To view these files please visit the journal online (http://dx.doi.org/10.1136/ bmjopen-2014-005862).

Received 5 June 2014 Revised 2 September 2014 Accepted 22 September 2014

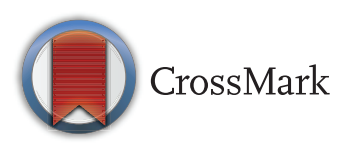

\footnotetext{
${ }^{1}$ University of Helsinki and Helsinki University Central Hospital; Cancer Center, HUSLAB and Clinical Chemistry, Helsinki, Finland ${ }^{2}$ The National Institute for Health and Welfare (THL), Helsinki, Finland

${ }^{3}$ Hjelt Institute, University of Helsinki, Helsinki, Finland
}

Correspondence to Dr Jari Haukka; jari.haukka@helsinki.fi

\section{ABSTRACT}

Objectives: Venous thromboembolism (VTE) continues to be a frequent medical emergency requiring rapid recognition so as to reach diagnosis and initiate anticoagulation therapy. The use of statins in addition to reducing the incidence of arterial thrombosis for decreasing the incidence and reoccurrence of VTE is reported. The aim of our study was to explore the association between statin usage and the incidence of new VTE at the population level during a 10-year follow-up.

Design: Population-based historic cohort.

Setting: The Health 2000 Survey was based on a nationally representative sample.

Participants: 8028 individuals aged 30 years or over in Finland.

Primary and secondary outcome measures: The primary end point event was the first ever hospitalisation due to one of the following causes: pulmonary embolism (International Classification of Diseases-10 I26), cerebral venous non-pyogenic thrombosis (163.6), or venous thrombosis (180.9-189). Results: The preselected explanatory variables applied to the Poisson regression model were statin usage (no/ yes) during follow-up (2000-2011) and several baseline data (age, sex; usage of blood glucose lowering drugs, vitamin $\mathrm{K}$ antagonists and antiplatelet agents). We observed 136 VTE events, the incidence of $1.72(95 \% \mathrm{Cl} 1.44$ to 2.04$)$ per 1000 person-years. Current statin usage did not associate with the incidence of VTE according to the univariate model (rate ratio (RR) $0.93,0.56$ to 1.52), but when adjusted with baseline variables (age, sex, medications) the RR declined to 0.60 ( 0.36 to $1.00, p=0.04$ ).

Conclusions: Statin use offers protection against first ever VTE events and appears as a primary prevention tool in patients without anticoagulation or antiplatelet medication.

\section{INTRODUCTION}

Venous thromboembolism (VTE) continues to be a frequent condition demanding medical emergency attention to reach diagnosis and initiate anticoagulation therapy.

\section{Strengths and limitations of this study}

- Population based with no selection bias at the start of follow-up.

- Long and complete follow-up information.

- Limited number of background variables and incidence events.

- The comprehensive use of prescribed drugs in this study could not be verified with certainty.

Mortality during the few months after VTE varies between $5 \%$ and $20 \%$, and patients often have other comorbidities, such as cardiovascular disease and cancer. The yearly incidence of VTE is $1-2 / 1000$ inhabitants in western societies. Currently, the traditional heparin and vitamin $\mathrm{K}$ antagonist (VKA) therapy followed by a course of temporal (36 months) or permanent VKA can be opted for with novel oral anticoagulants. ${ }^{1}$

The decision to either continue the anticoagulation for a few months or permanently depends on the acquired or inherited risk factor profile of the patient. This includes age above 60 years and concomitant illness, including cancer and inflammatory diseases as well as obesity, hormonal remedies and family history or severe thrombophilias (such as homozygosity of factor $\mathrm{V}$ Leiden or prothrombin mutation, double defects, antiphospholipid antibody syndrome), subjecting the patient to recurrent VTE. Despite the clinical evaluation, the recurrence rate of VTE continues to be $15-20 \%$ after an idiopathic event and around 5\% after a provoked thrombosis. ${ }^{1}$ Bleeding tendency needs to be regularly weighted also against the risk of thrombosis recurrence, while maintaining anticoagulation.

The use of statins has been reported to reduce the incidence of arterial thrombosis; also, interesting data on the decline of the incidence and reoccurrence of VTE have 
emerged. Retrospective observational and case-control studies as well as experimental evidence refer to the possibility that statins may also exert an antithrombotic effect in the venous system. A recent meta-analysis reported the association between VTE and $20-36 \%$ protection with statin use. ${ }^{2}$ A primary prevention trial of VTE with rosuvastatin in a randomised placebocontrolled design showed a $48 \%$ reduction in the incidence of VTE. ${ }^{3}$ Moreover, statin treatment alleviated the risk of recurrent pulmonary embolism (PE) by 50\% whether the patient used long-term VKA treatment or had stopped anticoagulation therapy, as reported by a Dutch population-based study with initially hospitalised patients. ${ }^{4}$ Finally, statins decrease the occurrence of VTE even in patients with cancer. ${ }^{5}$

Statins reduce the procoagulant activity of platelet membranes and downplay the signalling via low-density lipoprotein (LDL) receptors, which are engaged with the platelet activation. ${ }^{6}$ Statins also enhance fibrinolysis by reducing the plasminogen activator inhibitor-1 and triglyceride concentration. Also, other pleiotropic and anti-inflammatory mechanisms, including dampened tissue factor expression by monocytes, which can attenuate the risk of thrombosis, have been described.

The aim of the study was to explore the association between statin usage and incidence of the first ever VTE event in Finland. Our study utilises a nationally representative sample of 8028 persons aged $>30$ years ${ }^{7}$ of age in The Health 2000 Survey and a prospective observational pharmacoepidemiological design.

\section{MATERIAL AND METHODS}

Study population

The Health 2000 Survey was based on a nationally representative sample of 8028 individuals aged 30 years or over in Finland. To ensure a sample representative of the Finnish population, a two-stage stratified cluster sampling procedure was used. The baseline data collection from study patients took place between September 2000 and June 2001, and consisted of an interview and a comprehensive health examination. Of the study sample, 6986 patients $(87 \%)$ were interviewed at their home or in an institution, 6354 patients $(79 \%)$ took part in a comprehensive health examination and 416 patients $(5 \%)$ were examined at their home. ${ }^{7}$

\section{Follow-up time and end points}

The primary end point event of this study was the first hospitalisation due to one of the following causes: PE (International Classification of Diseases (ICD)-10 I26), cerebral infarction owing to cerebral venous nonpyogenic thrombosis (I63.6), or deep vein thrombosis (DVT), including thrombophlebitis of lower extremities (I80.0-I80.9). The information on end points was obtained from the National Hospital Discharge Register, which covers all hospitalisations in Finland starting from 1969 onwards. The 10-year follow-up was started at the beginning of The Health 2000 Study and was stopped at death, end of year 2011 or end point, whichever occurred first. The data regarding deaths were obtained from Statistics Finland. There were 103 individuals who recorded primary end point before the start of follow-up compatible with the general prevalence of the disease; these patients were excluded from the study population. Thus, the size of the study population at the start of follow-up was 7925 .

\section{Laboratory measurements}

Venous blood samples were drawn from the antecubital vein after a minimum of $4 \mathrm{~h}$ fasting. High-density lipoprotein (HDL) cholesterol, total cholesterol, triglyceride and plasma glucose concentrations were determined enzymatically (Roche Diagnostics, GmbH, Mannheim, Germany for HDL; and Olympus System Reagent, Hamburg, Germany for total cholesterol, triglycerides and glucose) with a clinical chemistry analyser (Olympus, AU400, Hamburg, Germany). ${ }^{8} \mathrm{C}$ reactive protein (CRP) concentrations were determined by a chemiluminescent immunometric assay (Immulite, Diagnostic Products, Los Angeles, California, USA) ${ }^{8}$ LDL cholesterol was calculated using the Friedewald formula. Plasma insulin and homocysteine concentrations were determined with microparticle enzyme immunoassay (Abbott Laboratories, Dainabot, Tokyo, Japan)..$^{9}{ }^{10}$ S-25(OH)D concentrations were measured by radioimmunoassay (Incstar, Stillwater, Minnesota, USA). ${ }^{11}$

\section{Drug information}

The data on the prescribed and purchased drugs were obtained from registers of the Social Insurance Institution. We had records of the following drugs classified by Anatomical Therapeutic Chemical (ATC) $\operatorname{code}^{12}$ : statins (C10AA), blood glucose lowering drugs excluding insulin (A10B), insulin (A10A), VKA (B01AA) and antiplatelet agents excluding heparin (B01AC), and over the counter acetylsalicylic acid. Regarding statins the data included all prescribed statins purchased during the follow-up period in 2000-2006 and 2008. Because there were no data available regarding the drug amounts purchased for years 2007 and 2009-2011, we calculated the mean amount of purchase based on available years and adapted it for the whole follow-up period. The time dependent variable for current statin usage was determined for each individual with the prescription data using R language package Epi. ${ }^{13}$ The follow-up time of each individual with statin exposure was cut into 6-month periods and the statin usage in each period was determined. For other drugs we had only the number of prescriptions at the baseline year 2000, which was used to construct a dichotomic variable of drug usage at baseline (no/yes).

\section{Statistical modelling}

We applied the Poisson regression model using end point event as a dependent variable, length of follow-up as an offset variable and statin usage (no/yes) during 
each time period as time-varying explanatory variable. The following variables were used as time-invariant variables measured at baseline: age (30-40, 40-50, 50-60, 60-70 and over 70 years), sex (male/female), blood glucose lowering drug usage, excluding insulins (no/ yes), insulin usage (no/yes), VKA usage (no/yes), antiplatelet agents (no/yes), blood glucose $(\mathrm{mmol} / \mathrm{L})$, total cholesterol $(\mathrm{mmol} / \mathrm{L})$, HDL cholesterol $(\mathrm{mmol} / \mathrm{L})$, LDL cholesterol $(\mathrm{mmol} / \mathrm{L})$, triglycerides $(\mathrm{mmol} / \mathrm{L})$, CRP $(\mathrm{mg} / \mathrm{L})$, vitamin $\mathrm{D}_{3}(\mathrm{nmol} / \mathrm{L})$, homocysteine $(\mu \mathrm{mol} / \mathrm{L})$ and insulin $(\mathrm{mU} / \mathrm{L})$. The values of the laboratory measurements were transformed to categorical variables defined by tertiles. We also estimated the inverse probability weights (IPW) to fit marginal structural models. ${ }^{14}$ IPW were estimated using age and sex in the numerator, and age, sex, usage of blood glucose lowering drugs other than insulin, VKA usage and use of antiplatelet agents in the denominator. In order to check survivor bias we carried out modelling without patients with prevalent statin use in start of follow-up ( $\mathrm{N}=460$ excluded $).{ }^{15}$

\section{RESULTS}

The size of the study population was 7925 , including 3589 men and 4336 women (table 1). We observed 136 VTE events during follow-up with incidence of 1.72 (95\% CI 1.44 to 2.04 ) per 1000 person-years during the mean follow-up time of 10 years (table 2). There were 64 events with diagnosis of PE (ICD-10 I26), 1 with sinus thrombosis (I636) and 71 with DVT (I80.0-I80.9).

In all there were 67532 statin prescriptions and 2083 individuals (26\% of the study population) had at least 1 prescription. Simvastatin (ATC code C10AA01) with 54\% of prescriptions and atorvastatin (C10AA05) with 23\% represented the most frequent active lipid-lowering substances. Current statin usage, which comprised $14 \%$ of all cumulated person-years, did not associate with the incidence of VTE according to the univariate model rate ratio (RR) 0.93 (0.56 to 1.52; table 2). The use of oral antidiabetic drugs at the baseline was associated with a threefold increased incidence (RR 3.32, 1.84 to 6.00 ), but insulin usage did not show any association. Using antithrombotic drugs associated with higher incidence (RR 4.55, 2.70 to 7.66).

Table 1 Baseline characteristics of study population

\begin{tabular}{lrr}
\hline Categorical variables and usage of drugs at baseline & & \\
\hline Sex & & $45 \%$ \\
$\quad$ Male & 3589 & $55 \%$ \\
Female & 4336 & $96 \%$ \\
Blood glucose lowering drug & 7637 & $4 \%$ \\
$\quad$ No & 288 & $98 \%$ \\
Yes & 7787 & $2 \%$ \\
Insulin & 138 & $96 \%$ \\
$\quad$ No & 7582 & $4 \%$ \\
Yes & 343 & $98 \%$ \\
Antithrombotic agent & & $2 \%$ \\
$\quad$ No & 7764 & $98 \%$ \\
Yes & 161 & $2 \%$ \\
Antiplatelet agent & 7732 & 193 \\
$\quad$ No & & \\
Yes & & \\
Vitamin K antagonists & & \\
$\quad$ No & & \\
Yes & & \\
\hline
\end{tabular}

Continuous variables at baseline LDL cholesterol (mmol/L)

\begin{tabular}{lcccccl}
\hline & 1st Qu & Median & Mean & 3rd Qu & SD & Missing \\
\hline Age & 42.0 & 52.0 & 54.7 & 66.0 & 16.1 & 0 \\
Blood glucose (mmol/L) & 5.0 & 5.3 & 5.6 & 5.7 & 1.3 & 1275 \\
Total cholesterol $(\mathrm{mmol} / \mathrm{L})$ & 5.1 & 5.9 & 5.9 & 6.6 & 1.1 & 1275 \\
HDL cholesterol $(\mathrm{mmol} / \mathrm{L})$ & 1.1 & 1.3 & 1.3 & 1.6 & 0.4 & 1275 \\
LDL cholesterol $(\mathrm{mmol} / \mathrm{L})$ & 3.1 & 3.8 & 3.8 & 4.5 & 1.2 & 1276 \\
Triglycerides $(\mathrm{mmol} / \mathrm{L})$ & 1.0 & 1.3 & 1.6 & 1.9 & 1.1 & 1275 \\
Ratio HDL/cholesterol & 18.0 & 22.0 & 23.0 & 28.0 & 7.4 & 1275 \\
CRP $(\mathrm{mg} / \mathrm{L})$ & 0.3 & 0.8 & 2.3 & 2.0 & 6.3 & 1694 \\
Vitamin $\mathrm{D}_{3}(\mathrm{nmol} / \mathrm{L})$ & 33.0 & 43.0 & 44.9 & 55.0 & 16.9 & 1825 \\
Homocysteine $(\mu \mathrm{mol} / \mathrm{L})$ & 9.2 & 11.0 & 12.0 & 13.5 & 5.1 & 1825 \\
Insulin $(\mathrm{mU} / \mathrm{L})$ & 5.0 & 7.0 & 9.6 & 11.0 & 30.3 & 1627 \\
\hline CRP, C reactive protein; HDL, high-density lipoprotein; LDL, low-density lipoprotein; Qu, quartile. & \multicolumn{7}{c}{}
\end{tabular}


Table 2 Incidence of end point events

\begin{tabular}{|c|c|c|c|c|c|c|c|c|}
\hline Variable & P-years (1000) & Events & Incidence $(1 / 1000)$ & $95 \% \mathrm{Cl}$ & & $\mathbf{R R}$ & $95 \% \mathrm{C}$ & \\
\hline Current statin & & & & & & & & \\
\hline No & 67.78 & 118 & 1.74 & 1.44 & 2.09 & & & \\
\hline Yes & 11.17 & 18 & 1.61 & 0.95 & 2.55 & 0.93 & 0.56 & 1.52 \\
\hline Sex & & & & & & & & \\
\hline Male & 36.02 & 53 & 1.47 & 1.1 & 1.93 & & & \\
\hline Female & 42.93 & 83 & 1.93 & 1.54 & 2.4 & 1.31 & 0.93 & 1.85 \\
\hline Age & & & & & & & & \\
\hline$(0,40]$ & 19.92 & 10 & 0.50 & 0.24 & 0.92 & & & \\
\hline$(40,50]$ & 20.22 & 15 & 0.74 & 0.41 & 1.22 & 1.48 & 0.66 & 3.29 \\
\hline$(50,60]$ & 17.11 & 24 & 1.40 & 0.90 & 2.09 & 2.79 & 1.34 & 5.84 \\
\hline$(60,70]$ & 11.05 & 28 & 2.53 & 1.68 & 3.66 & 5.05 & 2.45 & 10.39 \\
\hline$(70$, Inf $]$ & 10.65 & 59 & 5.54 & 4.22 & 7.15 & 11.04 & 5.65 & 21.58 \\
\hline Insulin usage & aseline & & & & & & & \\
\hline No & 77.83 & 133 & 1.71 & 1.43 & 2.03 & & & \\
\hline Yes & 1.12 & 3 & 2.68 & 0.55 & 7.83 & 1.57 & 0.50 & 4.92 \\
\hline Blood glucose & ering drug & & & & & & & \\
\hline No & 76.71 & 124 & 1.62 & 1.34 & 1.93 & & & \\
\hline Yes & 2.24 & 12 & 5.37 & 2.77 & 9.37 & 3.32 & 1.84 & 6.00 \\
\hline Antithrombotic & nt usage & & & & & & & \\
\hline No & 76.7 & 120 & 1.56 & 1.30 & 1.87 & & & \\
\hline Yes & 2.25 & 16 & 7.11 & 4.06 & 11.55 & 4.55 & 2.70 & 7.66 \\
\hline Antiplatelet ag & usage & & & & & & & \\
\hline No & 77.87 & 126 & 1.62 & 1.35 & 1.93 & & & \\
\hline Yes & 1.08 & 10 & 9.27 & 4.44 & 17.05 & 5.73 & 3.01 & 10.91 \\
\hline Vitamin $\mathrm{K}$ anta & ists usage & & & & & & & \\
\hline No & 77.7 & 128 & 1.65 & 1.37 & 1.96 & & & \\
\hline Yes & 1.25 & 8 & 6.42 & 2.77 & 12.66 & 3.90 & 1.91 & 7.97 \\
\hline Blood glucose & nol/L) & & & & & & & \\
\hline$[2.4,5.1]$ & 24.79 & 36 & 1.45 & 1.02 & 2.01 & & & \\
\hline$(5.1,5.6]$ & 23.93 & 31 & 1.30 & 0.88 & 1.84 & 0.89 & 0.55 & 1.44 \\
\hline$(5.6,26.7]$ & 18.69 & 48 & 2.57 & 1.89 & 3.40 & 1.77 & 1.15 & 2.72 \\
\hline Total cholester & nmol/L) & & & & & & & \\
\hline$[1.9,5.4]$ & 23.71 & 36 & 1.52 & 1.06 & 2.10 & & & \\
\hline$(5.4,6.3]$ & 21.33 & 33 & 1.55 & 1.06 & 1.02 & 0.64 & 1.63 & 1.02 \\
\hline$(6.3,11.7]$ & 22.38 & 46 & 2.06 & 1.50 & 1.35 & 0.88 & 2.09 & 1.35 \\
\hline HDL cholester & $\mathrm{nmol} / \mathrm{L})$ & & & & & & & \\
\hline$[0.23,1.13]$ & 22.39 & 45 & 2.01 & 1.46 & & & & \\
\hline$(1.13,1.45]$ & 22.45 & 33 & 1.47 & 1.01 & 0.73 & 0.47 & 1.15 & 0.73 \\
\hline$(1.45,3.41]$ & 22.57 & 37 & 1.64 & 1.15 & 0.82 & 0.53 & 1.26 & 0.82 \\
\hline LDL cholesterc & tmol/L) & & & & & & & \\
\hline$[0,3.3]$ & 22.56 & 34 & 1.51 & 1.04 & & & & \\
\hline$(3.3,4.2]$ & 22.79 & 38 & 1.67 & 1.18 & 1.11 & 0.70 & 1.76 & 1.11 \\
\hline$(4.2,8.8]$ & 22.06 & 43 & 1.95 & 1.41 & 1.29 & 0.82 & 2.03 & 1.29 \\
\hline Triglycerides ( & (l/L) & & & & & & & \\
\hline$[0.4,1.1]$ & 26.16 & 30 & 1.15 & 0.77 & & & & \\
\hline$(1.1,1.7]$ & 21.84 & 45 & 2.06 & 1.50 & 1.80 & 1.13 & 2.85 & 1.80 \\
\hline$(1.7,16.6]$ & 19.42 & 40 & 2.06 & 1.47 & 1.80 & 1.12 & 2.88 & 1.80 \\
\hline Ratio HDL/cho & erol & & & & & & & \\
\hline$[3,19]$ & 23.92 & 48 & 2.01 & 1.48 & & & & \\
\hline$(19,25.7]$ & 20.58 & 34 & 1.65 & 1.14 & 0.82 & 0.53 & 1.28 & 0.82 \\
\hline$(25.7,56]$ & 22.91 & 33 & 1.44 & 0.99 & 0.72 & 0.46 & 1.12 & 0.72 \\
\hline$C$ reactive prot & (mg/L) & & & & & & & \\
\hline$[0,0.39]$ & 22.26 & 22 & 0.99 & 0.62 & & & & \\
\hline$(0.39,1.41]$ & 21.62 & 42 & 1.94 & 1.40 & 1.97 & 1.17 & 3.29 & 1.97 \\
\hline$(1.41,191]$ & 20.53 & 40 & 1.95 & 1.39 & 1.97 & 1.17 & 3.32 & 1.97 \\
\hline Vitamin $D_{3}(n n$ & & & & & & & & \\
\hline$[5,36]$ & 20.55 & 35 & 1.70 & 1.19 & 2.37 & & & \\
\hline$(36,50]$ & 21.42 & 31 & 1.45 & 0.98 & 2.06 & 0.85 & 0.52 & 1.38 \\
\hline$(50,134]$ & 21.15 & 37 & 1.75 & 1.23 & 2.41 & 1.03 & 0.65 & 1.63 \\
\hline
\end{tabular}


Table 2 Continued

\begin{tabular}{|c|c|c|c|c|c|c|c|c|}
\hline Variable & P-years (1000) & Events & Incidence (1/1000) & $95 \% \mathrm{Cl}$ & & $\mathbf{R R}$ & $95 \% \mathrm{Cl}$ & \\
\hline \multicolumn{9}{|c|}{ Homocysteine ( $\mu \mathrm{mol} / \mathrm{L})$} \\
\hline$[3.7,9.7]$ & 22.15 & 18 & 0.81 & 0.48 & 1.29 & & & \\
\hline$(9.7,12.5]$ & 21.82 & 32 & 1.47 & 1.00 & 2.07 & 1.80 & 1.01 & 3.22 \\
\hline$(12.5,111]$ & 19.16 & 53 & 2.77 & 2.07 & 3.62 & 3.40 & 1.99 & 5.81 \\
\hline \multicolumn{9}{|l|}{ Insulin (mU/L) } \\
\hline$[1,5]$ & 22.72 & 26 & 1.14 & 0.75 & 1.68 & & & \\
\hline$(5,9]$ & 22.67 & 45 & 1.99 & 1.45 & 2.66 & 1.73 & 1.07 & 2.81 \\
\hline (92 200] & 19.64 & 33 & 1.68 & 1.16 & 2.36 & 1.47 & 0.88 & 2.00 \\
\hline
\end{tabular}

RR with $95 \% \mathrm{Cl}$ based on univariate Poisson regression model.

Laboratory measurements in tertiles ' $[a, b)$ ' means that interval $a-b$ is closed left and open right. The data on variables are collected at baseline.

HDL, high-density lipoprotein; LDL, low-density lipoprotein; RR, rate ratio.

Addition of more explanatory variables in the model substantially altered the association between statin usage and incidence (table 3). Adjusting for sex, age, baseline oral antidiabetic, insulin and use of antithrombotics (model II) reduced the RR to 0.60 (0.36 to 1.00$)$. Using IPW for the structural model (model III) decreased the RR further to 0.58 (0.35 to 0.96). Adjusting for baseline laboratory measurements also decreased slightly the estimate for statin effect, for example, adjusting for CRP gave a RR of $0.43(0.23$ to 0.81$)$. However, because of the missing laboratory measurements we do not report these results in further detail, for example, for CRP there were several (1694) missing values (table 2). Increased levels of LDL were associated with increasing incidence of VTE; the same occurred with homocysteine.

In addition, we looked for possible interactions between statin usage and age, sex, blood glucose lowering drugs usage (excluding use of insulin), VKA and

Table 3 RR with $95 \% \mathrm{Cl}$ of three Poisson regression models

\begin{tabular}{|c|c|c|c|c|c|c|c|c|c|}
\hline & \multicolumn{3}{|c|}{ Model I } & \multicolumn{3}{|c|}{ Model II } & \multicolumn{3}{|c|}{ Model III } \\
\hline & \multicolumn{3}{|c|}{ RR (95\% Cl) } & \multicolumn{3}{|c|}{ RR (95\% Cl) } & \multicolumn{3}{|c|}{ RR, IPW (95\% Cl) } \\
\hline \multicolumn{10}{|l|}{ Statin } \\
\hline No & \multicolumn{3}{|c|}{ (reference) } & \multicolumn{3}{|c|}{ (reference) } & \multicolumn{3}{|c|}{ (reference) } \\
\hline Current & 0.64 & 0.38 & 1.05 & 0.60 & 0.36 & 1.00 & 0.58 & 0.35 & 0.96 \\
\hline \multicolumn{10}{|l|}{ Age } \\
\hline Under 40 & \multicolumn{3}{|c|}{ (reference) } & \multicolumn{3}{|c|}{ (reference) } & \multicolumn{3}{|c|}{ (reference) } \\
\hline$(40,50]$ & 1.52 & 0.68 & 3.38 & 1.51 & 0.68 & 3.37 & 1.53 & 0.68 & 3.43 \\
\hline$(50,60]$ & 2.99 & 1.42 & 6.26 & 2.91 & 1.39 & 6.10 & 3.20 & 1.53 & 6.70 \\
\hline$(60,70]$ & 5.66 & 2.73 & 11.75 & 5.31 & 2.55 & 11.05 & 5.36 & 2.55 & 11.24 \\
\hline$(70, \operatorname{lnf}]$ & 11.68 & 5.94 & 22.95 & 9.92 & 4.99 & 19.74 & 9.93 & 4.95 & 19.92 \\
\hline \multicolumn{10}{|l|}{ Sex } \\
\hline Male & \multicolumn{3}{|c|}{ (reference) } & \multicolumn{3}{|c|}{ (reference) } & \multicolumn{3}{|c|}{ (reference) } \\
\hline Female & 1.02 & 0.72 & 1.45 & 1.02 & 0.72 & 1.46 & 0.99 & 0.70 & 1.41 \\
\hline \multicolumn{10}{|c|}{ Blood glucose lowering drug } \\
\hline No & & & & \multicolumn{3}{|c|}{ (reference) } & \multicolumn{3}{|c|}{ (reference) } \\
\hline Yes & & & & 1.89 & 0.98 & 3.63 & 1.63 & 0.86 & 3.11 \\
\hline \multicolumn{10}{|c|}{ Insulin usage } \\
\hline No & & & & \multicolumn{3}{|c|}{ (reference) } & \multicolumn{3}{|c|}{ (reference) } \\
\hline Yes & & & & 0.72 & 0.21 & 2.45 & 0.72 & 0.25 & 2.13 \\
\hline \multicolumn{10}{|c|}{ Vitamin $\mathrm{K}$ antagonists } \\
\hline No & & & & \multicolumn{3}{|c|}{ (reference) } & \multicolumn{3}{|c|}{ (reference) } \\
\hline Yes & & & & 1.46 & 0.69 & 3.07 & 1.38 & 0.68 & 2.80 \\
\hline \multicolumn{10}{|c|}{ Antiplatelet agents } \\
\hline No & & & & \multicolumn{3}{|c|}{ (reference) } & \multicolumn{3}{|c|}{ (reference) } \\
\hline Yes & & & & 2.33 & 1.20 & 4.53 & 2.60 & 1.42 & 4.76 \\
\hline
\end{tabular}


Table 4 Statin usage and sex, interaction model

\begin{tabular}{|c|c|c|c|c|c|c|c|c|}
\hline \multirow[b]{2}{*}{ No statin/male } & \multirow{2}{*}{$\begin{array}{l}\text { P-years } \\
30.57\end{array}$} & \multirow{2}{*}{$\begin{array}{l}\text { Events } \\
50\end{array}$} & \multicolumn{3}{|c|}{ Incidence $(95 \% \mathrm{CI})$} & \multicolumn{3}{|c|}{ RR (95\% Cl) } \\
\hline & & & 1.64 & 1.21 & 2.16 & (refe & & \\
\hline Statin/male & 5.45 & 3 & 0.55 & 0.11 & 1.61 & 0.20 & 0.06 & 0.65 \\
\hline No Statin/female & 37.21 & 68 & 1.83 & 1.42 & 2.32 & 0.87 & 0.60 & 1.27 \\
\hline Statin/female & 5.72 & 15 & 2.62 & 1.47 & 4.33 & 0.75 & 0.41 & 1.38 \\
\hline
\end{tabular}

platelet aggregation inhibitors. Interaction for sex and statin usage was significant $\left(\chi^{2}=6.310, \mathrm{df}=1, \mathrm{p}=0.012\right)$. Interestingly, it turned out that the incidence of VTE among the statin group for men was quite low (RR 0.22, 0.06 to 0.65 ), but for women such an association was not obvious (RR $0.75,0.41$ to 1.38 ), on comparing VTE with and without statin usage, respectively (table 4 ).

In sensitivity analyses without prevalent statin users there were 115 cases in the non-statin group and 10 cases in the statin group; unadjusted RR was $0.82(0.43$ to 1.56$)$ and adjusted was 0.63 (0.33 to 1.21$)$.

\section{DISCUSSION}

To the best of our knowledge, this is the first report studying the association between statin usage and VTE that utilises a nationally representative population sample. Our results during the 11 years of prospective follow-up on the incidence of VTE are in line with a recent meta-analysis, ${ }^{16}$ which showed the risk reduction of 0.89 (0.78 to 1.01) for VTE among statin users. The JUPITER study, which is the largest randomised trial, included 465 events and showed $36 \%$ reduction in VTE (RR $0.64,0.39$ to $1.06, \mathrm{p}=0.08) .^{3} 17$ Our study addressed new incidence of VTE, as those patients who had previously suffered from VTE (136/8028) were excluded from the study population. The prospective nature and large population-based design of pharmacoepidemiology are the strengths of our study.

In this freely living Finnish population sample we could demonstrate that statin use is associated with a reduction of the incidence of VTE, including DVT of the lower extremities, PE and one case of cerebrovascular sinus thrombosis. This adds to the confirmation that statins exert anticoagulant activity. ${ }^{2-5}$ Furthermore, it supports the idea that statin therapy could be implemented in patients at risk of VTE.

We observed that use of oral antidiabetic drugs at baseline was associated with a threefold-increased incidence (RR 3.32, 1.84 to 6.00) of VTE, which indicates that insulin-resistant patients carry a high risk of VTE and that oral antidiabetic drugs do not seem to alleviate this risk, while insulin may do so. ${ }^{18}$ The positive association between antithrombotic drugs and VTE is quite probably due to confounding by indication ${ }^{19}$; also, the co-occurrence of cardiovascular disease and VTE has been noted in several studies. ${ }^{20}$ The limitation of our study is based on the fact that over-the-counter aspirin use is not controlled. This is significant, as aspirin has been recently shown to inhibit the reoccurrence of idiopathic VTE. ${ }^{21}$

Men seemed to respond to statin use more favourably than did women, indicating a plausible hormonal regulation of the effect of statins. In women, we did not control for hormonal replacement therapy, which may be a confounding factor, and which is known to be a risk factor for VTE. ${ }^{22}{ }^{23}$ The well-known age-association in increasing the incidence of DVT and PE was evidenced also among our patients. Also, the overall incidence of VTE in Finland is compatible with what has been reported internationally. The protective association with incidence of VTE among the highest third tertile of HDL-LDL ratio, lowest homocysteine and CRP supports earlier results of these surrogate laboratory markers.

Several limitations must be kept in mind when evaluating results from any observational study based on record linkage of drug information. First, the comprehensive use of prescribed drugs in this study could not be verified with certainty and may be subject to misclassification. The prescription data do not contain information on drugs used in nursing homes; therefore, the misclassification of exposure is more likely among the older patient groups. Second, although model-based adjustments using regression and IPW were applied, it is always possible that residual confounding factors could influence the results. For example, statin usage may depend on variables that are not included in the statistical models; or the statistical models used in the analysis do not properly adjust for the confounding factors. The importance of adjusting for possible confounding effects is reflected by the large difference between estimates obtained from the univariate and multivariate models. On the other hand, the results based on the three models with different patterns of covariates and modelling technique remained nearly unchanged regarding the effect of current statin usage (table 3). This compatibility increases the credibility of the results, albeit the actual incidences are relatively low in numbers due to the natural incidence of 1-2 cases/1000 inhabitants annually. Also, the hospital records, which are nationally gathered, may suffer from inconsistencies. Recently, these were evaluated in a separate study which validated this form of data collection in PE, but not in DVT. ${ }^{24}$ Third, analyses without prevalent statin showed attenuated, not significant, effect, which may be due to lower effect and lower number of cases resulting in wider confidence limits. 
In conclusion, statin use offers protection against firstever VTE events. The elevated LDL cholesterol, CRP and homocysteine, as reported earlier, are also associated with the risk of new VTE. Statins appear as a primary prevention tool in patients with a high risk of VTE, exerting its best effect in the male population.

Contributors $\mathrm{JH}$ performed analyses and $\mathrm{RL}$ and $\mathrm{JH}$ drafted the work; the other authors revised it critically for important intellectual content. All authors contributed substantially to the conception and design of the work; acquisition and interpretation of the data; and have approved the final version of the work to be published.

Funding This study was funded by University of Helsinki and The National Institute for Health and Welfare, Finland (THL), and supported by a grant from the Finnish Heart Foundation (Sydänsäätiö).

Competing interests $\mathrm{JH}$ has had previous research agreements with Janssen-Cilag, Novartis, Orion Pharma, Abbott, Novo Nordisk Farma, Pfizer, Sanofi-Aventis, Astellas and Takeda. RL is a member of the advisory boards of Astra Zeneca, Bayer, Boehringer Ingelheim, CSL Behring, LFB, Novo Nordisk, and Pfizer.

Patient consent Obtained.

Ethics approval The Health 2000 Study was approved by the Ethics Committees of the National Public Health Institute (since 2009 the National Institute for Health and Welfare) and the Hospital District of Helsinki and Uusimaa.

Provenance and peer review Not commissioned; externally peer reviewed. Data sharing statement No additional data are available.

Open Access This is an Open Access article distributed in accordance with the Creative Commons Attribution Non Commercial (CC BY-NC 4.0) license which permits others to distribute, remix, adapt, build upon this work noncommercially, and license their derivative works on different terms, provided the original work is properly cited and the use is non-commercial. See: http:// creativecommons.org/licenses/by-nc/4.0/

\section{REFERENCES}

1. Kearon C, Akl EA, Comerota AJ, et al. Antithrombotic therapy for VTE disease: Antithrombotic Therapy and Prevention of Thrombosis, 9th ed: American College of Chest Physicians Evidence-Based Clinical Practice Guidelines. Chest 2012;141:e419S-94S.

2. Squizzato $A$, Galli $M$, Romualdi $E$, et al. Statins, fibrates, and venous thromboembolism: a meta-analysis. Eur Heart J 2010;31:1248-56.

3. Glynn RJ, Danielson E, Fonseca FAH, et al. A randomized trial of rosuvastatin in the prevention of venous thromboembolism. $N$ Engl $J$ Med 2009;360:1851-61.

4. Biere-Rafi S, Hutten BA, Squizzato $A$, et al. Statin treatment and the risk of recurrent pulmonary embolism. Eur Heart J 2013;34:1800-6.
5. Khemasuwan D, Divietro ML, Tangdhanakanond K, et al. Statins decrease the occurrence of venous thromboembolism in patients with cancer. Am J Med 2010;123:60-5.

6. Akkerman JWN. From low-density lipoprotein to platelet activation. Int J Biochem Cell Biol 2008;40:2374-8.

7. Aromaa A, Koskinen S. Health and functional capacity in Finland Baseline results of the health 2000 health examination survey. Helsinki, Finland: 2004. http://www.terveys2000.fi/julkaisut/baseline. pdf

8. Heistaro S. Methodology report: Health 2000 survey. Helsinki, Finland: Kansanterveyslaitos, 2008. http://lib.thl.fi:2345/http:/lib.thl. fi:2345/lib4/?PBFORMTYPE=01002\&TITLEID=49681\&SQS=1: $\mathrm{FIN}: 1:: 6: 50:: \mathrm{HTML} \& \mathrm{PL}=0$

9. Luotola K, Pietilä A, Zeller T, et al. Associations between interleukin-1 (IL-1) gene variations or IL-1 receptor antagonist levels and the development of type 2 diabetes. J Intern Med 2011;269:322-32.

10. Juonala M, Viikari JSA, Laitinen T, et al. Interrelations between brachial endothelial function and carotid intima-media thickness in young adults the cardiovascular risk in young finns study. Circulation 2004;110:2918-23.

11. Kauppi M, Impivaara O, Mäki J, et al. Vitamin D status and common risk factors for bone fragility as determinants of quantitative ultrasound variables in a nationally representative population sample. Bone 2009;45:119-24.

12. WHOCC-ATC/DDD Index. http://www.whocc.no/atc_ddd_index/ (accessed 11 Sep 2012).

13. Carstensen B, Plummer M, Laara E, et al. Epi: a package for statistical analysis in epidemiology. 2008. http://www.pubhealth.ku.dk/bxc/Epi/

14. Cole SR, Hernan MA. Constructing inverse probability weights for marginal structural models. Am J Epidemiol 2008;168:656-64.

15. Danaei G, Tavakkoli M, Hernán MA. Bias in observational studies of prevalent users: lessons for comparative effectiveness research from a meta-analysis of statins. Am J Epidemiol 2012;175:250-62.

16. Rahimi K, Bhala N, Kamphuisen P, et al. Effect of statins on venous thromboembolic events: a meta-analysis of published and unpublished evidence from randomised controlled trials. PLoS Med 2012;9:e1001310.

17. Ridker PM, Pradhan A, MacFadyen JG, et al. Cardiovascular benefits and diabetes risks of statin therapy in primary prevention: an analysis from the JUPITER trial. Lancet 2012;380:565-71.

18. Westerbacka J, Yki-Järvinen $\mathrm{H}$, Turpeinen $\mathrm{A}$, et al. Inhibition of platelet-collagen interaction an in vivo action of insulin abolished by insulin resistance in obesity. Arterioscler Thromb Vasc Biol 2002;22:167-72.

19. Psaty BM, Siscovick DS. Minimizing bias due to confounding by indication in comparative effectiveness research the importance of restriction. JAMA 2010;304:897-8.

20. Prandoni $\mathrm{P}$, Ghirarduzzi $\mathrm{A}$, Prins $\mathrm{MH}$, et al. Venous thromboembolism and the risk of subsequent symptomatic atherosclerosis. J Thromb Haemost 2006;4:1891-6.

21. Prandoni $P$, Noventa F, Milan M. Aspirin and recurrent venous thromboembolism. Phlebology 2013;28(Suppl 1):99-104.

22. Kemmeren JM, Algra A, Grobbee DE. Third generation oral contraceptives and risk of venous thrombosis: meta-analysis. BMJ 2001;323:131.

23. Shufelt $\mathrm{CL}$, Bairey Merz $\mathrm{CN}$. Contraceptive hormone use and cardiovascular disease. J Am Coll Cardiol 2009;53:221-31.

24. Casez P, Labarère J, Sevestre M-A, et al. ICD-10 hospital discharge diagnosis codes were sensitive for identifying pulmonary embolism but not deep vein thrombosis. J Clin Epidemiol 2010;63:790-7. 